\title{
Coflex interspinous implant placement leading to synovial cyst development: case report
}

\author{
Seba Ramhmdani, MD, ${ }^{1,2}$ Marc Comair, BA, ${ }^{3}$ Camilo A. Molina, MD, ${ }^{1,2}$ Daniel M. Sciubba, MD, ${ }^{1,2}$ and \\ Ali Bydon, MD ${ }^{1,2}$
}

1The Spinal Column Biomechanics and Surgical Outcomes Laboratory and ${ }^{2}$ Department of Neurosurgery, Johns Hopkins
University School of Medicine, Baltimore, Maryland; and ${ }^{3}$ Georgetown University, Georgetown College, Washington, DC

Interspinous process devices (IPDs) have been developed as less-invasive alternatives to spinal fusion with the goal of decompressing the spinal canal and preserving segmental motion. IPD implantation is proposed to treat symptoms of lumbar spinal stenosis that improve during flexion. Recent indications of IPD include lumbar facet joint syndrome, which is seen in patients with mainly low-back pain. Long-term outcomes in this subset of patients are largely unknown. The authors present a previously unreported complication of coflex (IPD) placement: the development of a large compressive lumbar synovial cyst. A 64-year-old woman underwent IPD implantation (coflex) at L4-5 at an outside hospital for low-back pain that occasionally radiates to the right leg. Postoperatively, her back and right leg pain persisted and worsened. MRI was repeated and showed a new, large synovial cyst at the previously treated level, severely compressing the patient's cauda equina. Four months later, she underwent removal of the interspinous process implant, bilateral laminectomy, facetectomy, synovial cyst resection, interbody fusion, and stabilization. At the 3-month follow-up, she reported significant back pain improvement with some residual leg pain. This case suggests that facet arthrosis may not be an appropriate indication for placement of coflex.

https://thejns.org/doi/abs/10.3171/2018.1.SPINE171360

KEYWORDS lumbar spinal stenosis; coflex interspinous implant; synovial cyst; surgical technique

$\mathrm{L}$ AMINECTOMY has been the gold-standard treatment of lumbar spinal stenosis (LSS). Decompression is augmented with fusion predominantly in cases of mechanical back pain secondary to segmental instability, severe facet arthropathy, and in patients with lumbar spondylolisthesis. ${ }^{33}$ Patients with LSS and concomitant lowerback pain have superior clinical outcomes when treated with spinal fusion compared with decompression alone or conservatively. ${ }^{13,16}$ In the long term, a subset of patients may develop adjacent-level disease, requiring extension of fusion. ${ }^{9}$ It still is a matter of controversy whether adjacentlevel disease is a result of fusion itself rather than the underlying degenerative process. ${ }^{29}$ Within the past 15 years, a new nonfusion technology based on placement of a flexible interspinous process device (IPD) has emerged. This implant acts as a constant distracting force between the spinous processes, claiming "indirect decompression" of the thecal sac and nerve roots. It causes focal kyphosis at the stenotic level, with a resultant increase in the diameter of the canal. IPD claims to preserve the range of motion at the implanted level (except in extension) and therefore is theorized to decrease adjacent-segment degeneration acceleration. ${ }^{35}$

The majority of IPDs are still in the investigational phase, and currently there are 2 available FDA-approved dynamic devices: coflex (Paradigm Spine, LLC) and Superion (VertiFlex Inc.). ${ }^{11}$ Large, randomized clinical trials with long-term follow-up are lacking..$^{12}$ More importantly, rates of adverse events and device failures are relatively high $(9.6 \%-33.8 \%){ }^{8,12,24-27,32,41}$ Insufficient symptomatic improvement and progression of degenerative disease, such as scoliosis and spondylolisthesis, often necessitate reintervention and increase the overall cost of treatment. ${ }^{18,19,36}$ The indications of IPDs are largely debatable; the devices were originally developed to treat patients with symptomatic neurogenic claudication and buttock

ABBREVIATIONS IPD = interspinous process device; LSS = lumbar spinal stenosis

SUBMITTED December 8, 2017. ACCEPTED January 24, 2018.

INCLUDE WHEN CITING Published online June 15, 2018; DOI: 10.3171/2018.1.SPINE171360. 


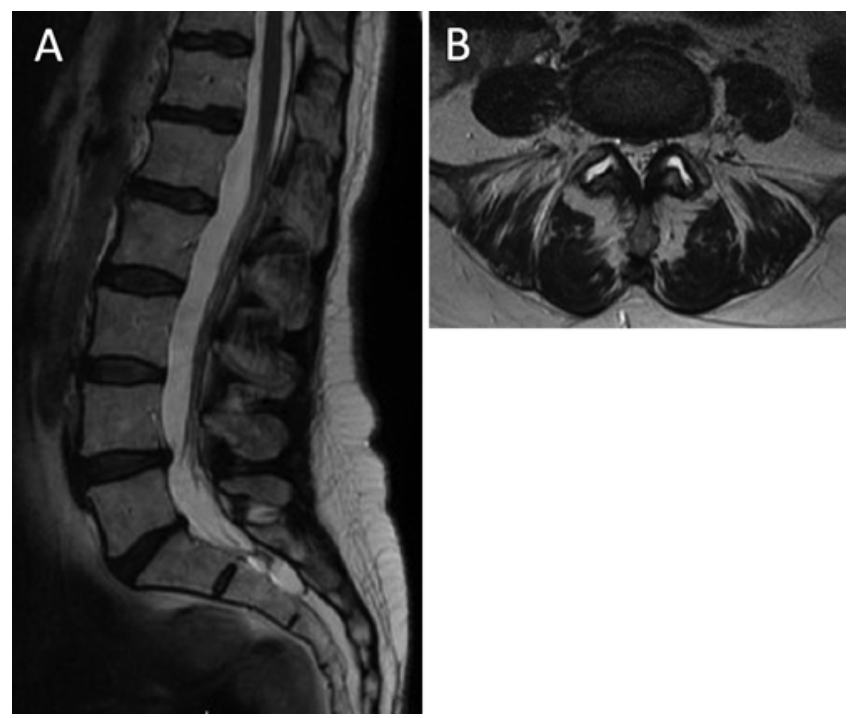

FIG. 1. Pre-coflex sagittal (A) and axial (B) T2-weighted MR images showing a diffuse disc bulge at the L4-5 level and significant facet hypertrophy with widening of the joint spaces. No listhesis is noted.

and leg pain that improves in flexion. Since then, there have been reports of expanding IPD indications for lowback pain without radiculopathy due to facet joint arthropathy or degenerative spondylolisthesis. ${ }^{5,7,10,17,36,42,44}$ The effect of interspinous implants on the progression of the degenerative process of the spine is unknown, and discrepancies - in both clinical and in vitro studies - indicate the need for further investigation. Herein, we report a previously unreported complication of IPD placement: massive synovial cyst development leading to thecal sac compromise.

\section{Case Report}

A 64-year-old woman complained of a 1-year history of predominantly lower-back pain and right lower-extremity radiculopathy. MRI scans showed a central disc protrusion at the L4-5 level and significant facet joint widening and hypertrophy (Fig. 1). The patient underwent placement of an IPD (coflex) at L4-5. Her lower-back pain persisted and worsened. Due to the worsening of her symptoms, a new postoperative MRI study was obtained 3 months after coflex insertion and revealed a very large synovial cyst, causing severe compression of her cauda equina (Fig. 2). The patient was referred to us with worsening lower-back and right leg pain. Her ambulation was rather limited due to pain, and her Numeric Rating Scale (NRS) score for pain was 6 . On physical examination, she had painful numbness in the right lower extremity, which was not present prior to coflex implant insertion; strength was preserved. She denied any traumatic events. A CT scan revealed an intact and appropriately placed coflex implant with bilateral distraction of the facet joints: widened distance between the L4 inferior articular process and L5 superior articular process (Fig. 3).

The patient was offered and chose to undergo coflex device removal, bilateral decompressive laminectomy, facetectomy, synovial cyst resection, discectomy with interbody fusion at the L4-5 level, and transpedicular instrumentation performed by the senior author. A large synovial cyst measuring $4 \times 2.2 \times 1.4 \mathrm{~cm}$ was confirmed in the surgical pathology report. At the 3-month followup, the patient reported a significant decrease in low-back pain with occasional but not insignificant persistent right leg pain. Her NRS pain score improved from 6 to 2, and she was able to ambulate without difficulty. Lumbar MRI demonstrated resolution of thecal sac compression (Fig. 4), and radiographs showed intact posterior spinal hardware at L4-5 (Fig. 5).

\section{Discussion}

The coflex IPD is a type of dynamic decompression device used to treat symptomatic degenerative lumbar disease. ${ }^{37}$ It is a titanium, U-shaped implant inserted between two adjacent spinous processes. The upper and lower arms
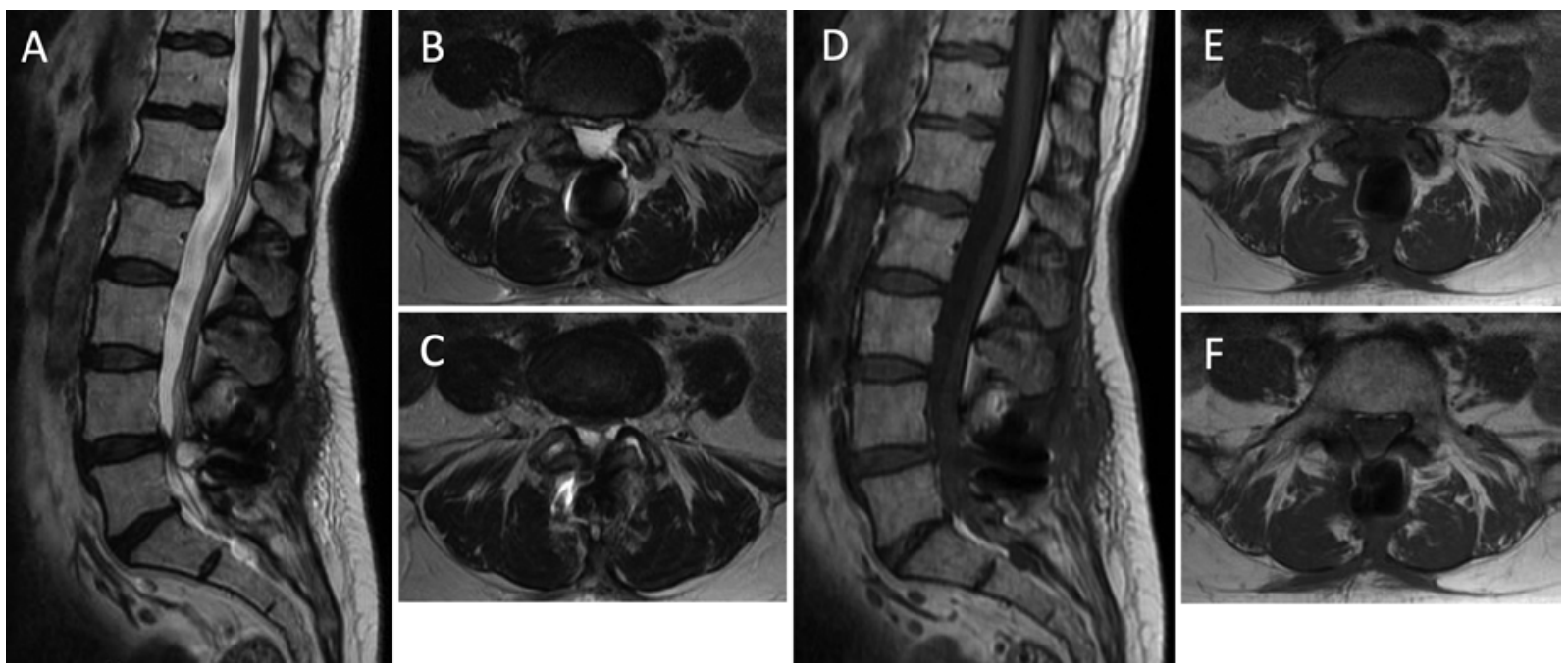

FIG. 2. Post-coflex sagittal and axial T2-weighted (A-C) and T1-weighted (D-F) MR images obtained 3 months after coflex insertion, illustrating bilateral synovial cyst herniation at the L4-5 level causing severe thecal sac compression. 

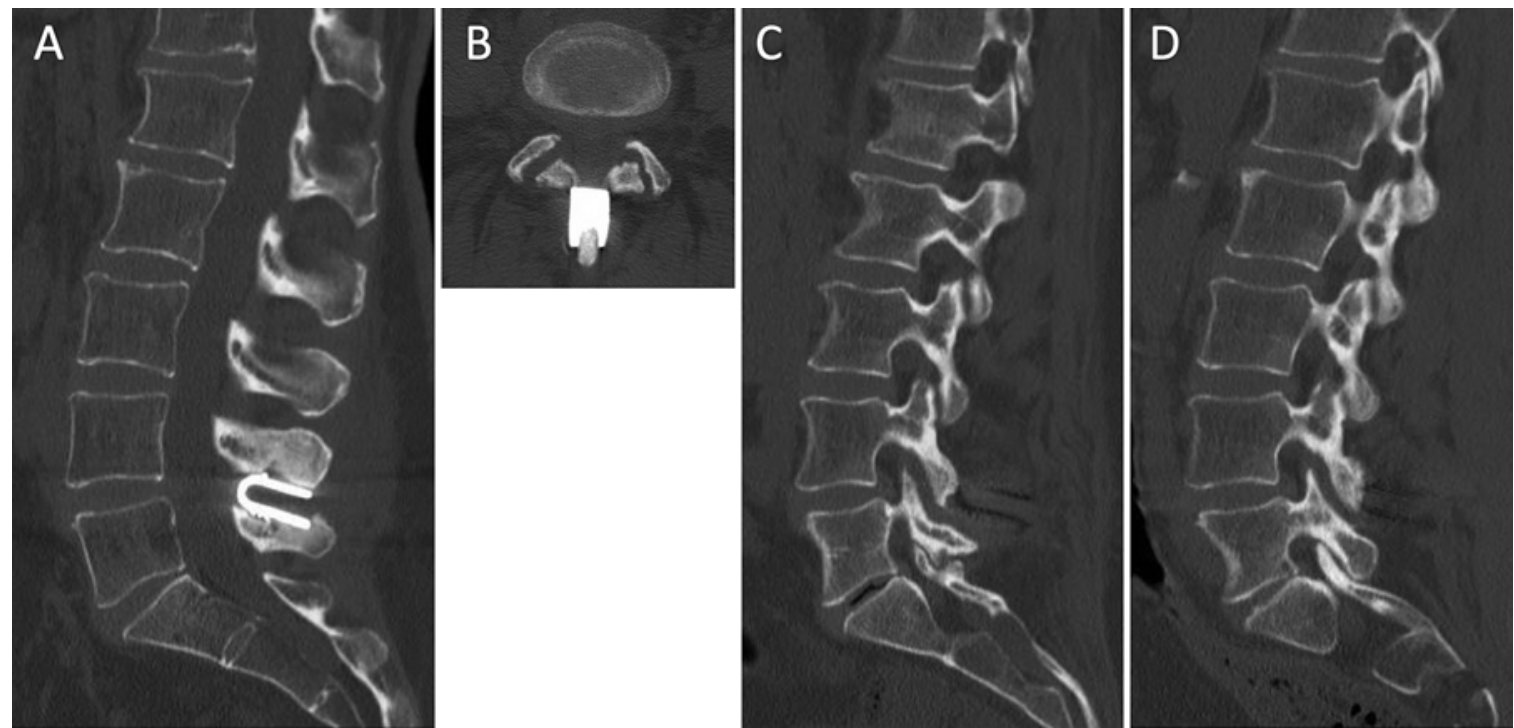

FIG. 3. Post-coflex midsagittal (A) and axial (B) CT scans showing the coflex device at the L4-5 interspinous process. Right (C) and left (D) parasagittal scans demonstrating the distracted facet joint at the L4-5 level where the coflex implant was placed. The distance between the inferior articulating process and the superior articulating process at the L4-5 facet joint was $4.2 \mathrm{~mm}$ compared with $1.1 \mathrm{~mm}$ at the L3-4 facet joint.

of the device are then fixed to the cranial and caudal spinal processes to prevent device movement. The characteristic "U" shape of the device grants its dynamic nature and helps to maintain the range of motion (flexion, axial rotation, and lateral bending) of the implanted lumbar segment. ${ }^{38}$ The conceptual design of IPDs is based on the fact that symptoms of spinal stenosis improve in flexion, commonly known as shopping cart sign. By distracting the spinous processes with a spacer or implant at the stenotic level, local kyphosis is created, leading to an increase in the diameter of the spinal canal at that level by $18 \%-22 \% .21,30,37,40$ Interspinous implants are hypothesized to exert their bio-
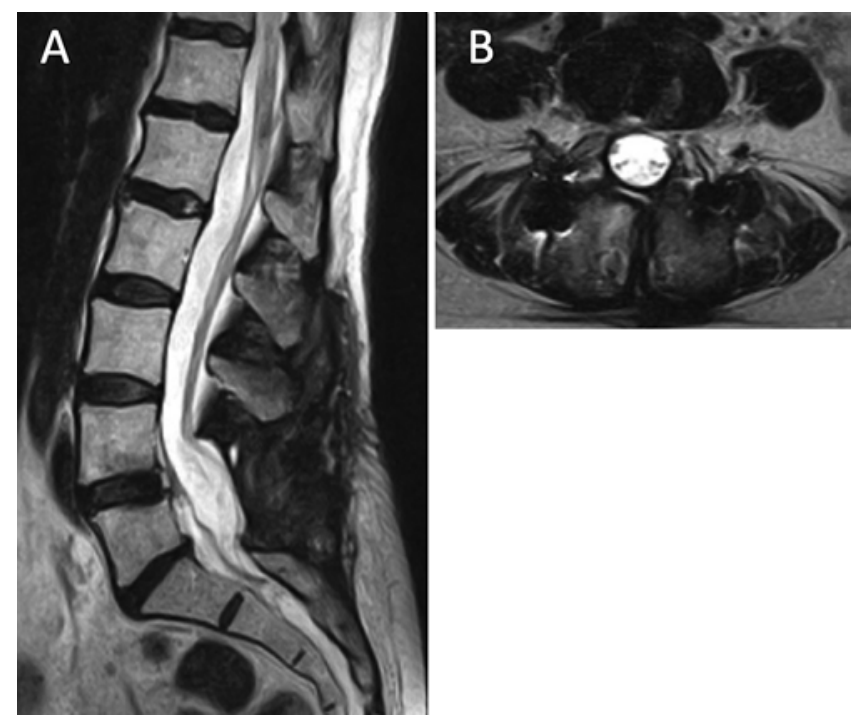

FIG. 4. Sagittal (A) and axial (B) T2-weighted MR images obtained after L4-5 laminectomy and posterior lumbar interbody fusion surgery, showing resolution of the synovial cyst and the neural foraminal stenosis. mechanical effect by preventing hyperextension without limiting other spinal motions..$^{23,26}$ In extension, the spinal canal is compressed by the posterior annulus fibrosis anteriorly and by the ligamentum flavum posteriorly. After insertion, the coflex implant distracts the interlaminar space; this distraction leads to supposed widening of the spinal canal by creating segmental kyphosis. Richards et al. obtained MRI scans of 8 lumbar spine specimens before and after interspinous spacer placement to investigate the ef-

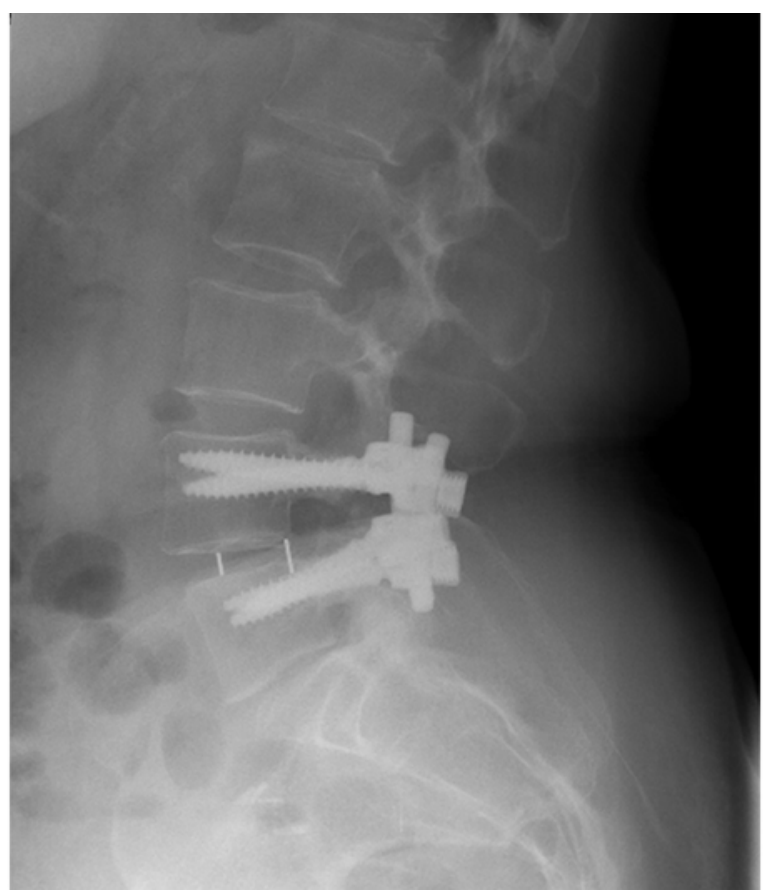

FIG. 5. Postoperative radiograph showing posterior segmental fixation at L4-5 with intervertebral graft. 
fect of distraction on spinal and foraminal dimensions. ${ }^{30}$ They found that after IPD insertion, the canal area was increased by $18 \%$ and the foraminal area by $25 \%$ during extension. However, this study should be interpreted with caution, as others have found "a weak correlation between the magnitude of radiographic improvement and the extent of pain relief (VAS) and clinical signs or symptoms."',34 Cases of over-distraction were associated with spinous process fracture, delayed fatigue fracture, and need for revision surgery.1,12

Another purported advantage of dynamic interspinous implants is their minimal effect on adjacent-level degeneration, as shown in a small, retrospective radiographic study. ${ }^{37}$ In a cadaveric in vitro study, Swanson et al. found that IPD insertion does not significantly change the pressure at the discs adjacent to the implanted level. ${ }^{35}$ This work was echoed by Lindsey et al., who reported that the motion of the adjacent levels was not affected by spacer insertion..$^{22}$ In a coflex postapproval clinical trial that compared the 3-year outcome of coflex instrumentation to posterolateral fusion, the reoperation rate at adjacent levels was $4.18 \%(9 / 215)$ of cases in the coflex group and $6.54 \%(7 / 107)$ in the fusion group. ${ }^{2}$ More recently, in a retrospective study of 87 patients with a 5-year follow-up, Yuan et al. reported a $4.8 \%$ reoperation rate for adjacentsegment disease (ASD) associated with the coflex device compared with $11.1 \%$ of cases treated with posterolateral fusion $(p=0.2777){ }^{43}$ This has not been corroborated with other long-term clinical follow-up studies.

The FDA approval of coflex was based on a clinical trial comprising 322 cases randomized to the coflex device or a pedicle screw fusion system in a 2:1 ratio. ${ }^{8}$ At the 2 -year follow-up, both groups had equivalent clinical outcomes; however, the reoperation rate in the coflex cohort was higher $(10.7 \%$ vs $7.5 \%, p=0.426)$. At 5 years, reoperation rates increased to $16.3 \%$ in the coflex cohort, with the majority of revision cases due to the persistence of symptoms. ${ }^{26}$ IPDs are theorized to offload the facet joint and decrease intervertebral disc pressure during extension. ${ }^{23,35,38}$ This quality encouraged the use of IPDs in the treatment of patients with predominantly low-back pain without neurogenic claudication or radiculopathy to limit the loss of range of motion associated with fusion. One of the recent indications of IPD is lumbar facet joint syndrome. ${ }^{5,6,15}$ In a prospective study by Cabraja et al., 20 patients with low-back pain caused by a diseased facet joint underwent coflex device implantation at the L4-5 level. ${ }^{6}$ All patients improved initially, but their conditions deteriorated 24 months after index surgery. The authors suggested that the reason for pain recurrence was the progression of degenerative diseases of the lumbar spine. With the increased usage of IPDs to treat predominantly low-back pain, there is a parallel increase in the reports of complications. Tamburrelli et al. observed for 2 years a series of 19 patients with residual pain after IPD insertion..$^{36}$ Of the 19 patients, 4 were suffering from predominantly lowback pain secondary to degenerative disc disease (2 patients) and adult scoliotic deformity (2 patients). The cause of IPD failure and pain persistance in these patients was "indication error." Barbagallo et al. reported on the clinical outcomes of 69 patients treated with an interspinous spacer for LSS. ${ }^{3}$ They found that 2 patients who presented with facet-joint arthrosis underwent revision with fusion for spinous process fracture after 1 week and 6 months in both patients. Given the limited number of published studies, the true incidence of revisions and device failures could be higher. ${ }^{25}$

Reoperation due to instability was reported by Zang et al. who found that patients in 3 of 133 cases treated with the coflex device had postoperative worsening of pain due to degenerative spondylolysis or sagittal instability at a mean of 27.6 months. ${ }^{44}$ Verhoof et al. documented a $67 \%$ reoperation rate in patients with grade I spondylolisthesis treated with an interspinous process spacer and recommended that any degree of spondylolisthesis should be considered a contraindication for X-STOP (St. Francis Medical Technologies, Inc.) spacer placement. ${ }^{39}$ Recently, Bohm et al. reported on 6 cases of interspinous device removal after a mean of 35.8 months due to worsening of symptoms with recurrent LSS and/or spondylolisthesis. ${ }^{4}$ According to the literature, the overall reoperation rate after coflex implantation ranges widely $(0 \%-16.3 \%))^{8,12,26,31,42-44}$ Few biomechanical reports of the effects of the coflex device on spinal segment stability are available, and most of them have demonstrated conflicting results. ${ }^{14,23,38,40}$ In 2006, Tsai et al. published on the impact of different loading forces at the L4-5 segment using the coflex device in cadavers. They found that the implanted segment displayed stability during flexion, extension, and axial rotation, but not during lateral bending. ${ }^{38}$ In 2008 , Wilke et al. found that the coflex device had a stabilizing influence on the lumbar spine specimens only during extension. ${ }^{40}$ Most recently, Lo et al. reported that lumbar decompression with coflex placement does not stabilize the lumbar level in flexion. ${ }^{23}$ They also described that the magnitude of the "gripping force" applied during coflex device implantation was different between the previous studies ${ }^{38,40}$ and was not comparable to the magnitude of force applied by the surgeon intraoperatively.

The facet joint is an essential component of the lumbar motion segment; it provides stability and facilitates load transfer between 2 adjacent pedicles. Facet joint arthropathy is common in the elderly as a result of repetitive compressive, shear, and axial loading forces. ${ }^{37} \mathrm{~A}$ diseased joint is less likely to accommodate normal spinal motion and subsequently is predisposed to lumbar instability. Alternatively, implantation of an IPD clearly changes the dynamic characteristics of the motion segment; posterior column distraction decreases the lordosis of the lumbar level, changes weight-bearing points anteriorly and posteriorly, and accelerates the degenerative process. ${ }^{12,28}$ Moreover, except in extension, an IPD does not offer passive resistance of load in all other spinal motions. ${ }^{20}$ In the case presented, it is possible that after coflex implant insertion, the distracting force overstretched the wall of the widened facet joint and increased stress tension at the capsule. With a distracted, widened facet joint and preserved motion, the mechanical compensation eventually failed at the weakest part of the joint, leading to synovial cyst development and herniation. This raises concern about one of the current indications of IPD placement: low-back pain due to painful facet arthrosis. 


\section{Conclusions}

A 64-year-old patient with lumbar stenosis and painful facet arthrosis underwent placement of the coflex motion-preserving IPD. The patient's symptoms persisted and worsened, leading to repeat MRI 3 months after IPS implantation. The images revealed a massive compressive synovial cyst, which was treated with IPD removal, lumbar laminectomy, facetectomy, synovial cyst resection, interbody fusion, and transpedicular instrumentation. In patients with low-back pain due to facet arthropathy, the implantation of IPDs should be approached with caution.

\section{References}

1. Alfieri A, Gazzeri R, Prell J, Scheller C, Rachinger J, Strauss C, et al: Role of lumbar interspinous distraction on the neural elements. Neurosurg Rev 35:477-484, 2012

2. Bae HW, Davis RJ, Lauryssen C, Leary S, Maislin G, Musacchio MJ Jr: Three-year follow-up of the prospective, randomized, controlled trial of coflex interlaminar stabilization vs instrumented fusion in patients with lumbar stenosis. Neurosurgery 79:169-181, 2016

3. Barbagallo GM, Olindo G, Corbino L, Albanese V: Analysis of complications in patients treated with the X-Stop interspinous process decompression system: proposal for a novel anatomic scoring system for patient selection and review of the literature. Neurosurgery 65:111-120, 2009

4. Bohm PE, Anderson KK, Friis EA, Arnold PM: Grade 1 spondylolisthesis and interspinous device placement: removal in six patients and analysis of current data. Surg Neurol Int 6:54, 2015

5. Buric J, Pulidori M: Long-term reduction in pain and disability after surgery with the interspinous device for intervertebral assisted motion (DIAM) spinal stabilization system in patients with low back pain: 4-year follow-up from a longitudinal prospective case series. Eur Spine J 20:1304-1311, 2011

6. Cabraja M, Abbushi A, Woiciechowsky C, Kroppenstedt S: The short- and mid-term effect of dynamic interspinous distraction in the treatment of recurrent lumbar facet joint pain. Eur Spine J 18:1686-1694, 2009

7. Davis R, Auerbach JD, Bae H, Errico TJ: Can low-grade spondylolisthesis be effectively treated by either coflex interlaminar stabilization or laminectomy and posterior spinal fusion? Two-year clinical and radiographic results from the randomized, prospective, multicenter US investigational device exemption trial: clinical article. J Neurosurg Spine 19:174-184, 2013

8. Davis RJ, Errico TJ, Bae H, Auerbach JD: Decompression and Coflex interlaminar stabilization compared with decompression and instrumented spinal fusion for spinal stenosis and low-grade degenerative spondylolisthesis: two-year results from the prospective, randomized, multicenter, Food and Drug Administration Investigational Device Exemption trial. Spine (Phila Pa 1976) 38:1529-1539, 2013

9. de la Garza-Ramos R, Kerezoudis P, Sciubba DM, Bydon A, Witham TF, Bydon M: The effect of preoperative diagnosis on the incidence of adjacent segment disease after lumbar fusion. J Neurosurg Sci 62:4-9, 2018

10. Errico TJ, Kamerlink JR, Quirno M, Samani J, Chomiak RJ: Survivorship of Coflex interlaminar-interspinous implant. SAS J 3:59-67, 2009

11. Gala RJ, Russo GS, Whang PG: Interspinous implants to treat spinal stenosis. Curr Rev Musculoskelet Med 10:182188, 2017

12. Gazzeri R, Galarza M, Neroni M, Fiore C, Faiola A, Puzzilli $\mathrm{F}$, et al: Failure rates and complications of interspinous pro- cess decompression devices: a European multicenter study. Neurosurg Focus 39(4):E14, 2015

13. Ghogawala Z, Dziura J, Butler WE, Dai F, Terrin N, Magge SN, et al: Laminectomy plus fusion versus laminectomy alone for lumbar spondylolisthesis. N Engl J Med 374:14241434,2016

14. Kettler A, Drumm J, Heuer F, Haeussler K, Mack C, Claes $\mathrm{L}$, et al: Can a modified interspinous spacer prevent instability in axial rotation and lateral bending? A biomechanical in vitro study resulting in a new idea. Clin Biomech (Bristol, Avon) 23:242-247, 2008

15. Kim KA, McDonald M, Pik JH, Khoueir P, Wang MY: Dynamic intraspinous spacer technology for posterior stabilization: case-control study on the safety, sagittal angulation, and pain outcome at 1-year follow-up evaluation. Neurosurg Focus 22(1):E7, 2007

16. Kleinstück FS, Grob D, Lattig F, Bartanusz V, Porchet F, Jeszenszky D, et al: The influence of preoperative back pain on the outcome of lumbar decompression surgery. Spine (Phila Pa 1976) 34:1198-1203, 2009

17. Kong DS, Kim ES, Eoh W: One-year outcome evaluation after interspinous implantation for degenerative spinal stenosis with segmental instability. J Korean Med Sci 22:330-335, 2007

18. Landi A, Gregori F, Grasso G, Mancarella C, Delfini R: Comment on "Controversies about interspinous process devices in the treatment of degenerative lumbar spine diseases: past, present, and future.” BioMed Res Int 2017:6545361, 2017

19. Landi A, Marotta N, Tarantino R, Ruggeri AG, Cappelletti M, Ramieri A, et al: Microsurgical excision without fusion as a safe option for resection of synovial cyst of the lumbar spine: long-term follow-up in mono-institutional experience. Neurosurg Rev 35:245-253, 2012

20. Lazaro BC, Brasiliense LB, Sawa AG, Reyes PM, Theodore $\mathrm{N}$, Sonntag VK, et al: Biomechanics of a novel minimally invasive lumbar interspinous spacer: effects on kinematics, facet loads, and foramen height. Neurosurgery 66 (3 Suppl Operative): $126-133,2010$

21. Lee J, Hida K, Seki T, Iwasaki Y, Minoru A: An interspinous process distractor (X STOP) for lumbar spinal stenosis in elderly patients: preliminary experiences in 10 consecutive cases. J Spinal Disord Tech 17:72-78, 2004

22. Lindsey DP, Swanson KE, Fuchs P, Hsu KY, Zucherman JF, Yerby SA: The effects of an interspinous implant on the kinematics of the instrumented and adjacent levels in the lumbar spine. Spine (Phila Pa 1976) 28:2192-2197, 2003

23. Lo CC, Tsai KJ, Chen SH, Zhong ZC, Hung C: Biomechanical effect after Coflex and Coflex rivet implantation for segmental instability at surgical and adjacent segments: a finite element analysis. Comput Methods Biomech Biomed Engin 14:969-978, 2011

24. Lønne G, Johnsen LG, Rossvoll I, Andresen H, Storheim K, Zwart JA, et al: Minimally invasive decompression versus $\mathrm{X}$-Stop in lumbar spinal stenosis: a randomized controlled multicenter study. Spine (Phila Pa 1976) 40:77-85, 2015

25. Moojen WA, Arts MP, Bartels RH, Jacobs WC, Peul WC: Effectiveness of interspinous implant surgery in patients with intermittent neurogenic claudication: a systematic review and meta-analysis. Eur Spine J 20:1596-1606, 2011

26. Musacchio MJ, Lauryssen C, Davis RJ, Bae HW, Peloza JH, Guyer RD, et al: Evaluation of decompression and interlaminar stabilization compared with decompression and fusion for the treatment of lumbar spinal stenosis: 5-year follow-up of a prospective, randomized, controlled trial. Int J Spine Surg 10:6, 2016

27. Patel VV, Whang PG, Haley TR, Bradley WD, Nunley PD, Davis RP, et al: Superion interspinous process spacer for intermittent neurogenic claudication secondary to moderate 
lumbar spinal stenosis: two-year results from a randomized controlled FDA-IDE pivotal trial. Spine (Phila Pa 1976) 40:275-282, 2015

28. Puzzilli F, Gazzeri R, Galarza M, Neroni M, Panagiotopoulos K, Bolognini A, et al: Interspinous spacer decompression (X-STOP) for lumbar spinal stenosis and degenerative disk disease: a multicenter study with a minimum 3-year followup. Clin Neurol Neurosurg 124:166-174, 2014

29. Radcliff K, Curry P, Hilibrand A, Kepler C, Lurie J, Zhao W, et al: Risk for adjacent segment and same segment reoperation after surgery for lumbar stenosis: a subgroup analysis of the Spine Patient Outcomes Research Trial (SPORT). Spine (Phila Pa 1976) 38:531-539, 2013

30. Richards JC, Majumdar S, Lindsey DP, Beaupré GS, Yerby SA: The treatment mechanism of an interspinous process implant for lumbar neurogenic intermittent claudication. Spine (Phila Pa 1976) 30:744-749, 2005

31. Röder C, Baumgärtner B, Berlemann U, Aghayev E: Superior outcomes of decompression with an interlaminar dynamic device versus decompression alone in patients with lumbar spinal stenosis and back pain: a cross registry study. Eur Spine J 24:2228-2235, 2015

32. Schmier JK, Halevi M, Maislin G, Ong K: Comparative cost effectiveness of Coflex ${ }^{\circledR}$ interlaminar stabilization versus instrumented posterolateral lumbar fusion for the treatment of lumbar spinal stenosis and spondylolisthesis. Clinicoecon Outcomes Res 6:125-131, 2014

33. Schroeder GD, Kepler CK, Kurd MF, Vaccaro AR, Hsu WK, Patel AA, et al: Rationale for the surgical treatment of lumbar degenerative spondylolisthesis. Spine (Phila Pa 1976) 40:E1161-E1166, 2015

34. Sobottke R, Schlüter-Brust K, Kaulhausen T, Röllinghoff M, Joswig B, Stützer H, et al: Interspinous implants (X Stop, Wallis, Diam) for the treatment of LSS: is there a correlation between radiological parameters and clinical outcome? Eur Spine J 18:1494-1503, 2009

35. Swanson KE, Lindsey DP, Hsu KY, Zucherman JF, Yerby SA: The effects of an interspinous implant on intervertebral disc pressures. Spine (Phila Pa 1976) 28:26-32, 2003

36. Tamburrelli FC, Proietti L, Logroscino CA: Critical analysis of lumbar interspinous devices failures: a retrospective study. Eur Spine J 20 (Suppl 1):S27-S35, 2011

37. Trautwein FT, Lowery GL, Wharton ND, Hipp JA, Chomiak RJ: Determination of the in vivo posterior loading environment of the Coflex interlaminar-interspinous implant. Spine J 10:244-251, 2010

38. Tsai KJ, Murakami H, Lowery GL, Hutton WC: A biome- chanical evaluation of an interspinous device (Coflex) used to stabilize the lumbar spine. J Surg Orthop Adv 15:167-172, 2006

39. Verhoof OJ, Bron JL, Wapstra FH, van Royen BJ: High failure rate of the interspinous distraction device (X-Stop) for the treatment of lumbar spinal stenosis caused by degenerative spondylolisthesis. Eur Spine J 17:188-192, 2008

40. Wilke HJ, Drumm J, Häussler K, Mack C, Steudel WI, Kettler A: Biomechanical effect of different lumbar interspinous implants on flexibility and intradiscal pressure. Eur Spine J 17:1049-1056, 2008

41. Wu AM, Zhou Y, Li QL, Wu XL, Jin YL, Luo P, et al: Interspinous spacer versus traditional decompressive surgery for lumbar spinal stenosis: a systematic review and meta-analysis. PLoS One 9:e97142, 2014

42. Xu C, Ni WF, Tian NF, Hu XQ, Li F, Xu HZ: Complications in degenerative lumbar disease treated with a dynamic interspinous spacer (Coflex). Int Orthop 37:2199-2204, 2013

43. Yuan W, Su QJ, Liu T, Yang JC, Kang N, Guan L, et al: Evaluation of Coflex interspinous stabilization following decompression compared with decompression and posterior lumbar interbody fusion for the treatment of lumbar degenerative disease: a minimum 5-year follow-up study. J Clin Neurosci 35:24-29, 2017

44. Zang L, Hai Y, Su QJ, Lu SB, Zhang CS, Yang JC, et al: [Device implanted complications of Coflex interspinous dynamic stabilization.] Zhonghua Wai Ke Za Zhi 50:782-787, 2012 (Chinese)

\section{Disclosures}

Dr. Sciubba: Consulting relationships with Medtronic, DePuySynthes, Stryker, NuVasive, K2M.

\section{Author Contributions}

Conception and design: Bydon, Ramhmdani. Acquisition of data: Bydon, Ramhmdani. Analysis and interpretation of data: Bydon, Ramhmdani. Drafting the article: all authors. Critically revising the article: all authors. Reviewed submitted version of manuscript: all authors. Approved the final version of the manuscript on behalf of all authors: Bydon. Study supervision: Bydon.

\section{Correspondence}

Ali Bydon: The Johns Hopkins Hospital, Baltimore, MD. abydon1@jhmi.edu. 